\title{
The Effectiveness and Efficiency of Medical Images after Special Filtration from the View of Medical Specialist An Application on Khartoum Hospital-Sudan
}

\author{
Mohamed Y. Adam \\ Training and Community \\ Service Center \\ King Saud University, \\ Riyadh, KSA
}

\author{
Dr. Mozamel M. Saeed \\ Collage of Science, Dept. of \\ Computer Science \\ Prince Sattam Bin Abdul-Aziz \\ University, KSA
}

\author{
Prof. Dr. Al Samani A. Ahmed \\ Computer Science \\ Al Neelain University \\ Khartoum, Sudan,
}

\begin{abstract}
There are many factors which have influences on the quality of medical images, so this paper gives a brief narration on the important techniques that produce acceptable quality to medical images. To ensure the validity of this techniques towards medical images, a questionnaire was designed and distributed to a number of doctors and professionals. The survey aims to assess the medical image specialists by regarding their point of views towards the impact of filtering medical images after processing using these techniques. MatLab package used to apply the techniques.
\end{abstract}

Keywords: Enhance, Logarithmic Transformations, Median Filtering, Histogram Equalization, Noise.

\section{INTRODUCTION}

Although modern digital cameras offer a great service to users in terms of facilitating the acquisition of images, but the user still needs to improve some of the images, which are unclear when taking the picture because of many reasons. The difference in light intensity from one location to another causes the instability of contrast, misty appearance and blurred colours. Therefore, in this paper different algorithms have been used to improve the images because they have a great effect on adjusting the lighting in dark images, clarifying their edges, clarifying their features and improving image quality[1]-[2].

In general, there are many things that make images to appear un normal such as: the resolution is poor, i.e. to increase the size of some details of the image, appearance of many types of noise and blurring caused by motion or lack of focus.

There are many techniques that are used to enhance an image including Logarithmic Transformations, Median Filtering, Histogram Equalization. The enhanced image obtained from the global area, histogram equalization will affect the intensity saturation in darkness area and whiteness areas. The colour image enhancement will be obtained by encoding the colour of red, green and blue to three different spectral images[1],[3][5].

\section{IMAGE ENHANCEMENT TECHNIQUES}

The image enhancement process aims to display certain features of the images for analysis or viewing. Medical images often suffer from one or more of the following defects:

- low resolution (in the spatial and spectral domains);

- high level of noise;

- low contrast;

- geometric deformations;

-presence of imaging artifacts.
These imperfections can be inherent to the imaging modality (e.g., X-rays offer low contrast for soft tissues, ultrasound produces very noisy images, and metallic implants will cause imaging artefacts in MRI) or the result of a deliberate tradeoff during acquisition. For example, finer spatial sampling may be obtained through a longer acquisition time. This would also increase the probability of patient movement and thus blurring. In this paper, we will only be concerned with enhancing the medical images and we will not be interest in the challenging problem of designing optimal procedures for their acquisition.[7]-[9].

\section{HISTOGRAM EQUALIZATION}

The histogram equalization algorithm improves image contrast by converting image intensity values so that the resulting image graph is flat. Histogram Equalization is one of the most important techniques used to access high-quality images in colour scales in medical applications such as Xray, MRI, CT scan. In order to identify diseases and correct diagnosis, these images require high resolution and colour variation.

To implement the histogram equalization on the image, you must obtain the probability density function and the cumulative density function of the image. This makes you able to calculate the number of pixels per colour in the image, and produce a cumulative total count. Then, by changing the output size, we can implement the histogram equation.

You can also implement the histogram equalization by reading the pixel density, looking for it in the pixel set and then measuring it accordingly to set the new pixel value. For the chart specification, a brief description is given here [6]-[7],[13].

Type the action that graphically displays a histogram. This will help you visualize the changes made by the graph balancing process and its specifications in an image. Below are MatLab commands to perform the above operations, as well as some other basic processes. In MatLab, we use the following commands.

img = imread (imageName); 


$$
\begin{aligned}
& \text { imGray = rgb2gray(img); } \\
& \text { myHist = imhist(imGray); } \\
& \text { eqImage = imhisteq(imGray); } \\
& \text { figure, imshow(imGray); } \\
& \text { figure, imshow(eqImage); }
\end{aligned}
$$

In order to view the histogram of the image, you will supply two output arguments to the function for histogram equalization. The output arguments are the transformation function and the equalized image respectively. This is given as follows:

[eqImage, transfFunc] = imhisteq(imGray);

figure, plot(transfFunc);

figure, imshow(eqImage);

The second and third lines display the transformation function and the equalized image respectively.

In order to perform histogram specification, we use the same function as before (histeq), but include a specified histogram as the second argument as in the first line below

[imSpec, transSpec] = histeq(img, specPDF);

figure, imshow(imSpec), title('Matched Image');

[imSpecEq, transfSpecEq] = histeq(imSpec);

figure, plot(transfSpecEq), title('Specified Image

Histogram...');

The second line simply displays the matched image, the third line gets the histogram of the matched image, and the last line plots the histogram, which should match the specified PDF.

\section{TYPES OF NOISE IN DIGITAL \\ IMAGES}

The image is usually composed of a set of discrete elements called pixels. The values of pixels that have an offset or motion create the noise in the image. Noise can appear through the cameras or through the image transfer process on different modes of transport.

If you want to restore the original image, noise must be removed. The noise in the image affects the application of the image processing algorithms so that the results are incorrect. There are need to filter the image before applying the algorithms.

\section{MEDIAN FILTERING}

The most important filter from nonlinear filters is the median filter, which is used extensively in noise removal in a way that makes the picture retain its details. The median filter depends on where the noise is located and then is removed and replaced by the average of the neighborhood pixels, while the other points remain unchanged.

The median filter will be generated from the below equation where the pixel value of a point $p$ is replaced by the result of median of pixels value of eight neighborhood of the point $p$.

$$
g(p)=\operatorname{median}\left\{f(p) \text { where } p \in N_{g}(p)\right\} \text { (1) }
$$

The median value will replace the central pixel according to

\begin{tabular}{|c|c|c|c|c|}
\hline 123 & 125 & 126 & 130 & 140 \\
\hline 122 & 124 & 126 & 127 & 135 \\
\hline 118 & 120 & 150 & 125 & 134 \\
\hline 119 & 115 & 119 & 123 & 133 \\
\hline 111 & 116 & 110 & 120 & 130 \\
\hline
\end{tabular}
brightness of the neighbouring pixels.

For example, we can calculate the median value of pixel neighbourhood of 150 , as we can see in figure 1 below, and then is replaced with the median of surrounding pixels value that is 124 . We use here $\mathrm{A} 3 \times 3$ square neighbourhood

Figure (1): Neighbourhood values

As a result, the median value of the neighbourhood is: 124 The median filter advantages include:

- the contrast will not be changed because of the output values available from the present neighbourhood.

-Boundaries do not shift in median filtering that can happen with other filters.

-The outliers values will be removed because the median is less sensitive to the extreme values than the mean.

\section{LOGARITHMIC TRANSFORMATIONS}

If you want to increase the light intensity of the image, you have to use logarithmic transform. It is also often use to increase contrast for lower intensity values.

In MATLAB, the equation used to get the Logarithmic transform of image $f$ is:

$\mathrm{g}=\mathrm{c} * \log (1+\operatorname{double}(\mathrm{f}))$

The constant $\mathrm{c}$ is usually used to scale the range of the log function to match the input domain. In this case $\mathrm{c}=255 / \log (1+255)$ for a uint 8 image, or $\mathrm{c}=1 / \log (1+1)(\sim 1.45)$ for a double image. It can also be used to further increase contrast - the higher the $\mathrm{c}$, the brighter the image will appear. By using this way, the log function can produce values too bright to be displayed.

Notice that when $\mathrm{c}=5$, the image is the brightest and you can see the radial lines on the inside of the medical image (these lines are barely viewable in the original because there is not enough contrast in the lower intensities).

The MATLAB code that created the image I when $\mathrm{c}=1, \mathrm{c}=2$, and $\mathrm{c}=3$ is:

Notice the loss of detail in the bright regions where intensity values are clamped. Any values greater than one, produced from the scaling, are displayed as having a value of 1 (full intensity) and should be clamped. Clamping in MATLAB can be performed by the min(matrix, upper_bound),

Although logarithms may be calculated in different bases such as MATLAB's builtin $\log 10, \log 2$ and $\log$ (natural $\log$ ), the resulting curve, when the range is scaled to match the domain, is the same for all bases. The shape of the curve is dependent instead on the range of values it is applied to. It is important to be aware of this effect if you plan to use logarithm transformations successfully.

Note that for domain $[0,1]$ the effects of the logarithm transform are barely noticeable, while for domain [0,65535] the effect is extremely exaggerated. Also note that, unlike with linear scaling and clamping, gross detail is still visible in light areas. 


\section{The Results of the Questionnaire about the Application}

To ensure the validity of these techniques, a questionnaire was designed and distributed to a number of doctors and professionals. In dealing with medical images, there were positive results to demonstrate the validity of these techniques for the purpose it was designed for.

Section 1: General information of interviewer

\begin{tabular}{|l|c|c|}
\multicolumn{2}{|c}{ Table(1): sex } \\
\begin{tabular}{|l|c|c|}
\hline & Freq & $\%$ \\
\hline male & 13 & 65 \\
\hline female & 7 & 35 \\
\hline Total & 20 & 100 \\
\hline
\end{tabular}
\end{tabular}

Table(2):age

\begin{tabular}{|l|c|c|}
\hline & Freq & \% \\
\hline $30-$ less than 40 & 13 & 65 \\
\hline 40- less than 50 & 7 & 35 \\
\hline Total & 20 & 100 \\
\hline
\end{tabular}

Table(3):job

\begin{tabular}{|c|c|c|}
\hline & Freq & $\%$ \\
\hline Doctor & 7 & 35 \\
\hline $\begin{array}{ll}\text { Medical image } \\
\text { technician }\end{array}$ & 13 & 65 \\
\hline Total & 20 & 100 \\
\hline
\end{tabular}

Table(4):Years of Experience

\begin{tabular}{|l|c|c|}
\hline & Freq & \% \\
\hline less than 5 & 5 & 25 \\
\hline 5-less than 10 & 5 & 25 \\
\hline 10-less than 20 & 10 & 50 \\
\hline Total & 20 & 100 \\
\hline
\end{tabular}

Table(5):Further education in the area of medical image processing techniques is important:

\begin{tabular}{|l|c|c|}
\hline & Freq & \% \\
\hline Yes & 17 & 85 \\
\hline No & 3 & 15 \\
\hline Total & 20 & 100 \\
\hline
\end{tabular}

Table(6):In case the medical image is up normal: The treatment will be as follows:

\begin{tabular}{|l|c|c|}
\hline & Freq & \% \\
\hline Repeating & 6 & 30 \\
\hline Processing & 14 & 70 \\
\hline Total & 20 & 100 \\
\hline
\end{tabular}

Section 2: The effects of medical image processing techniques using MatLab package:

a) Histogram equalization technique.

Origin medical image

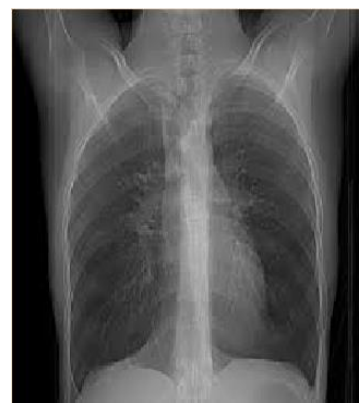

Processed medical image

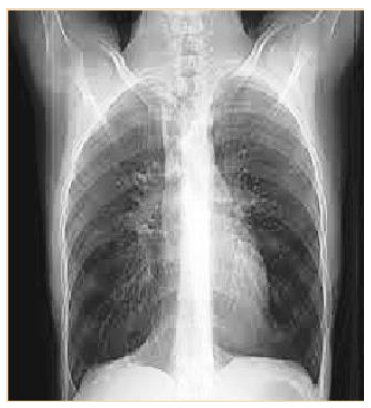

Figure (2): Applying histogram equalization

TABLE(7): THE RESULT OF HISTOGRAM EQUALIZATION TECHNIQUE QUESTIONS

\begin{tabular}{|c|c|c|c|c|c|c|}
\hline \multirow{2}{*}{ Question } & & \multicolumn{3}{|c|}{ Answer } & \multirow{2}{*}{ Average } & \multirow{2}{*}{ Result } \\
\hline & & Yes & Neutral & No & & \\
\hline \multirow{2}{*}{$\begin{array}{l}\text { 1.The resolution in processed medical } \\
\text { image is better than the origin medical } \\
\text { image }\end{array}$} & Freq & 19 & 1 & 0 & \multirow{2}{*}{1.05} & \multirow{2}{*}{ Yes } \\
\hline & $\%$ & 95.0 & 5.0 & 0 & & \\
\hline \multirow{2}{*}{$\begin{array}{l}\text { 2.The contrast Sensitivity in processed } \\
\text { medical image is better than origin } \\
\text { medical image. }\end{array}$} & Freq & 13 & 7 & 0 & \multirow{2}{*}{1.35} & \multirow{2}{*}{ Yes } \\
\hline & $\%$ & 65 & 35 & 0 & & \\
\hline \multirow{2}{*}{$\begin{array}{l}\text { 3.Noises in processed medical image are } \\
\text { less than in the origin medical image. }\end{array}$} & Freq & 18 & 2 & 0 & \multirow{2}{*}{1.1} & \multirow{2}{*}{ Yes } \\
\hline & $\%$ & 90.0 & 10.0 & 0 & & \\
\hline \multirow{2}{*}{$\begin{array}{l}\text { 4.The blur in processed medical image } \\
\text { is less than in the origin medical image. }\end{array}$} & Freq & 13 & 7 & 0 & \multirow{2}{*}{1.35} & \multirow{2}{*}{ Yes } \\
\hline & $\%$ & 65 & 35 & 0 & & \\
\hline
\end{tabular}


International Journal of Computer Applications Technology and Research

Volume 7-Issue 06, 208-214, 2018, ISSN:-2319-8656

\begin{tabular}{|l|c|c|c|c|c|c|}
\hline $\begin{array}{l}\text { 5.In general the processed medical } \\
\text { image (new medical image) is better } \\
\text { than the origin medical image in order } \\
\text { to diagnose }\end{array}$ & Freq & 19 & 1 & 0 & 1.05 & Yes \\
\cline { 2 - 5 } & $\%$ & 95.0 & 5.0 & 0 & & \\
\hline Total Result
\end{tabular}

Through table(7) above shows that most respondents agree that the resulting image after processing is better than the original image, depending on the trio scale likart

b) Median filter technique.

Origin medical image

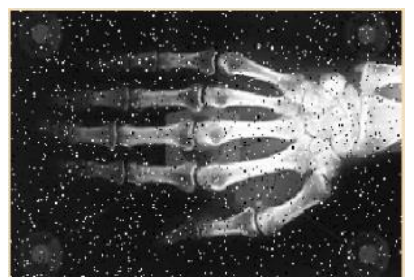

Processed medical image

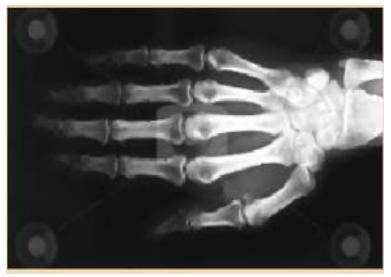

Figure (3): Applying Median filter technique

TABLE(8): THE RESUlT OF MEDIAN FILTER TECHNIQUE QUESTIONS

\begin{tabular}{|c|c|c|c|c|c|c|}
\hline \multirow{2}{*}{ Question } & & \multicolumn{3}{|c|}{ Answer } & \multirow{2}{*}{ Average } & \multirow{2}{*}{ Result } \\
\hline & & Yes & Neutral & No & & \\
\hline \multirow{2}{*}{$\begin{array}{l}\text { 1.The resolution in processed medical } \\
\text { image is better than the origin medical } \\
\text { image }\end{array}$} & Freq & 20 & 0 & 0 & \multirow{2}{*}{1} & \multirow{2}{*}{ Yes } \\
\hline & $\%$ & 100 & 0 & 0 & & \\
\hline \multirow{2}{*}{$\begin{array}{l}\text { 2. The contrast Sensitivity in processed } \\
\text { medical image is better than origin } \\
\text { medical image. }\end{array}$} & Freq & 13 & 7 & 0 & \multirow{2}{*}{1.35} & \multirow{2}{*}{ Yes } \\
\hline & $\%$ & 65 & 35 & 0 & & \\
\hline \multirow{2}{*}{$\begin{array}{l}\text { 3.Noises in processed medical image are } \\
\text { less than in the origin medical image. }\end{array}$} & Freq & 18 & 2 & 0 & \multirow{2}{*}{1.1} & \multirow{2}{*}{ Yes } \\
\hline & $\%$ & 90.0 & 10.0 & 0 & & \\
\hline \multirow{2}{*}{$\begin{array}{l}\text { 4.The blur in processed medical image is } \\
\text { less than in the origin medical image. }\end{array}$} & Freq & 13 & 7 & 0 & \multirow[t]{2}{*}{1.35} & \multirow{2}{*}{ Yes } \\
\hline & $\%$ & 65 & 35 & 0 & & \\
\hline \multirow{2}{*}{$\begin{array}{l}\text { 5.In general the processed medical image } \\
\text { (new medical image) is better than the } \\
\text { origin medical image in order to diagnose }\end{array}$} & Freq & 20 & 0 & 0 & \multirow[t]{2}{*}{1} & \multirow[t]{2}{*}{ Yes } \\
\hline & $\%$ & 100 & 0 & 0 & & \\
\hline Total Result & & & & & 1.12 & Yes \\
\hline
\end{tabular}

Through table(8) above shows that most respondents agree that the resulting image after processing is better than the original image, depending on the trio scale likart.

c) Logarithm transformation

Original

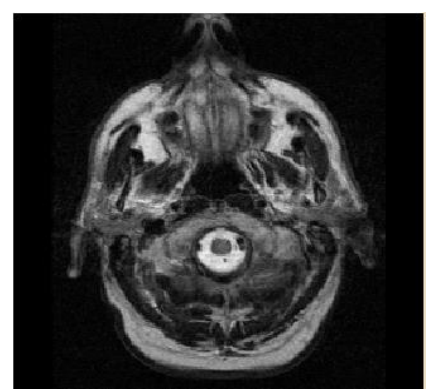

Processed

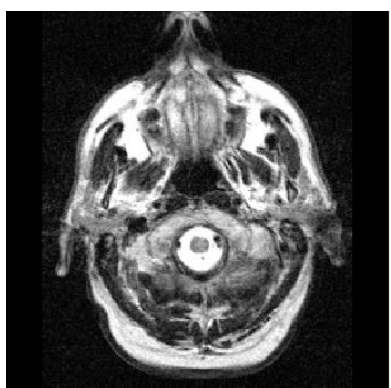

Figure(4): Applying Logarithm transformation 
International Journal of Computer Applications Technology and Research

Volume 7-Issue 06, 208-214, 2018, ISSN:-2319-8656

TABLE(9): THE RESULT OF LOGARITHM TRANSFORMATION TECHNIQUE QUESTIONS

\begin{tabular}{|c|c|c|c|c|c|c|}
\hline \multirow[b]{2}{*}{ Question } & & \multicolumn{3}{|c|}{ Answer } & \multirow[b]{2}{*}{ Average } & \multirow[b]{2}{*}{ Result } \\
\hline & & Yes & $\begin{array}{l}\text { Neutr } \\
\text { al }\end{array}$ & No & & \\
\hline \multirow{2}{*}{$\begin{array}{l}\text { 1.The resolution in processed medical } \\
\text { image is better than the origin medical } \\
\text { image }\end{array}$} & Freq & 18 & 2 & 0 & \multirow{2}{*}{1.1} & \multirow{2}{*}{ Yes } \\
\hline & $\%$ & 90.0 & 10.0 & 0 & & \\
\hline \multirow{2}{*}{$\begin{array}{l}\text { 2.The contrast Sensitivity in processed } \\
\text { medical image is better than origin medical } \\
\text { image. }\end{array}$} & Freq & 13 & 7 & 0 & \multirow{2}{*}{1.35} & \multirow{2}{*}{ Yes } \\
\hline & $\%$ & 65 & 35 & 0 & & \\
\hline \multirow{2}{*}{$\begin{array}{l}\text { 3.Noises in processed medical image are } \\
\text { less than in the origin medical image. }\end{array}$} & Freq & 18 & 2 & 0 & \multirow{2}{*}{1.1} & \multirow{2}{*}{ Yes } \\
\hline & $\%$ & 90.0 & 10.0 & 0 & & \\
\hline \multirow[t]{2}{*}{$\begin{array}{l}\text { 4.The blur in processed medical image is } \\
\text { less than in the origin medical image. }\end{array}$} & Freq & 13 & 7 & 0 & \multirow{2}{*}{1.35} & \multirow{2}{*}{ Yes } \\
\hline & $\%$ & 65 & 35 & 0 & & \\
\hline \multirow{2}{*}{$\begin{array}{l}\text { 5.In general the processed medical image } \\
\text { (new medical image) is better than the } \\
\text { origin medical image in order to diagnose }\end{array}$} & Freq & 20 & 0 & 0 & \multirow[t]{2}{*}{1} & \multirow[t]{2}{*}{ Yes } \\
\hline & $\%$ & 100 & 0 & 0 & & \\
\hline \multicolumn{5}{|l|}{ Total Result } & 1.12 & Yes \\
\hline
\end{tabular}

Through table(9) above shows that most respondents agree that the resulting image after processing is better than the original image, depending on the trio scale likart.

\section{CONCLUSION}

The main goal of this study is to build an application to enhance medical images using effective enhancement algorithms including histogram equalization, Median filter technique, Logarithm transformation. The developed application has been tested and deployed by the staff of Khartoum hospital. According to the view of medical specialists, these algorithms are powerful method for image enhancement and they will increase the contrast of image. The results are plotted in the above tables.

The proposed methods have been implemented by the strongest and most popular program in Computational Libraries (MATLAB).

\section{REFERENCES}

[1] Achmad, B., M.M. Mustafa and A. Hussain,'Warped optical-flow inter-frame reconstruction for ultrasound image enhancement.",jcssp.1532.1540DOI:10.3844, .2011.

[2] Charles Henry Brase \& Corrinne Pellillo Brase, Understandable Statistics: Concepts and Methods, 2014

[3] D.A. Forsyth and J. Ponce, Computer Vision - A Modern Approach, Prentice Hall, 2003

[4] Gregory d Abram, Parallel image generation, with anti-aliasing and texturing. University of North Crolina Chapel Hill NC27599-3175

[5] Image Processing using Matlab. Second Edition. United States of America. Gatesmark Publishing.

[6] Mohamed Y. Adam, Mozamel M. Saeed and Al Samani A. Ahmed, "Medical Image Enhancement Application Using Histogram Equalization in Computational Libraries", International Journal of Computer Science and Telecommunications, Volume 6, Issue 1, January 2015, pp 712, http://www.ijcst.org/Volume6/Issue1/p2_6_1.pdf

[7] Mohamed Y. Adam, Mozamel M. Saeed and Al Samani A. Ahmed, " THE EFFECT OF IMPLEMENTING OF NONLINEAR FILTERS FOR ENHANCING MEDICAL IMAGES USING MATLAB", International Journal of Computer Science \& Information Technology (IJCSIT) Vol 7, No 6, December 2015

http:// www .aircconline.com/ijcsit/V7N6/7615ijcsit05.pdf

[8] Mrozek, Bogumiła - Mrozek, Zbigniew., Matlab 6; Poradnikużytkownika, 2010.
[9] Nayan Patel, Abhishek Shah, MayurMistry, "Astudy of Digital Image Filtering Techniques in Spatial Image Processing", International Conference on Convergence of Technology 2014

[10] Ozimek and Agnieszka b., Digital image processing. Materials from Lecture no. 7. Cracow. Cracow University of Technology, 2010

[11] Processing using Matlab. Second Edition. United States of America. Gatesmark Publishing.

[12] Rafael C. Gonzalez and Richard E. Woods, Digital image processing, Third edition, Prentice Hall, 2008

[13] Rakesh M.R, Ajeya B, Mohan A.R,"Hybrid Median Filter for Impulse Noise Removal of an Image in Image Restoration",International Journal of Advanced Research in Electrical, Electronics and Instrumentation Engineering, Vol. 2 , Issue $10, \quad$ October 2013 , http://ijareeie.com/upload/2013/october/8QHybrid.pdf

[14] Sigurd angenent, eric pichon, and allen tannenbaum, "mathematical methods in medical image processing", http://www.math.wisc.edu/ angenent/preprints/medicalBAMS. pdf

[15] The MarthWorks, Image Processing Toolbox 6 User's Guide. United States of America. The MathWorks, 2009.

[16] Warner and David , Digital Image processing - an analytic approach Prentice Hall ,2003

\section{Appendix:}

\section{Code:}

a.function pushbutton4_Callback(hObject, eventdata, handles)

global im

GIm=im;

numofpixels=size $(\mathrm{GIm}, 1) * \operatorname{size}(\mathrm{GIm}, 2)$;

HIm=uint8(zeros(size (GIm,1),size (GIm,2)));

freq $=$ zeros $(256,1)$;

probf=zeros $(256,1)$;

probc $=$ zeros $(256,1)$;

cum=zeros $(256,1)$;

output=zeros $(256,1)$;

for $\mathrm{i}=1$ :size $(\mathrm{GIm}, 1)$

for $\mathrm{j}=1$ :size $(\mathrm{GIm}, 2)$

value $=\operatorname{GIm}(\mathrm{i}, \mathrm{j})$;

freq $($ value +1$)=$ freq $($ value +1$)+1$;

$\operatorname{probf}($ value +1$)=$ freq $($ value +1$) /$ numofpixels; 
International Journal of Computer Applications Technology and Research

Volume 7-Issue 06, 208-214, 2018, ISSN:-2319-8656

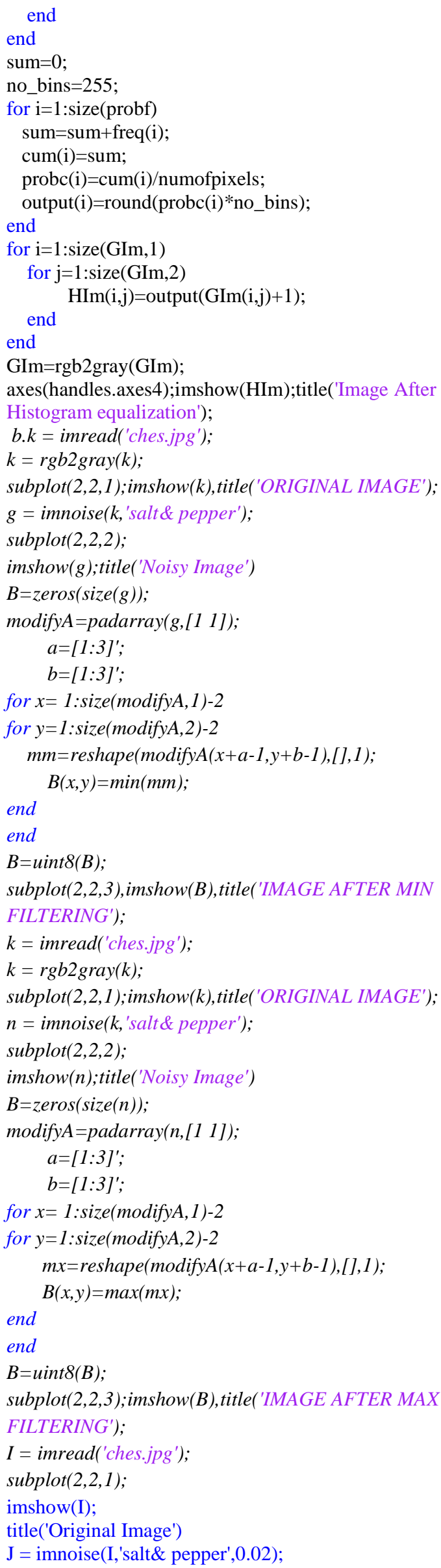

Histogram

subplot(2,2,1);imshow(k),title('ORIGINAL IMAGE');

$g$ = imnoise ( $k$,'salt\& pepper');

subplot (2,2,2);

imshow (g);title('Noisy Image')

$B=z \operatorname{eros}(\operatorname{size}(g))$;

$a=[1: 3]^{\prime}$;

$b=[1: 3]^{\prime}$

for $x=1: \operatorname{size}(\operatorname{modify} A, 1)-2$

for $y=1$ :size(modifyA,2)-2

$m m=$ reshape $($ modify $A(x+a-1, y+b-1),[], 1)$

end

end

$B=\operatorname{uint} 8(B)$

subplot(2,2,3),imshow(B),title('IMAGE AFTER MIN

$k=$ imread('ches.jpg');

$k=\operatorname{rgb} 2 \operatorname{gray}(k)$

subplot(2,2,1);imshow(k),title('ORIGINAL IMAGE');

$n=$ imnoise $(k$,'salt \& pepper');

subplot $(2,2,2)$

$a=[1: 3]^{\prime} ;$

$b=[1: 3]^{\prime}$;

for $x=1:$ size (modifyA, 1)-2

for $y=1$ :size (modifyA,2)-2

$m x=$ reshape $($ modify $A(x+a-1, y+b-1),[], 1)$;

end

end

subplot(2,2,3);imshow(B),title('IMAGE AFTER MAX

FILTERING');

$I=$ imread('ches.jpg'),

subplot $(2,2,1)$

title('Original Image')

$\mathrm{J}=$ imnoise $(\mathrm{I}$, 'salt\& pepper',0.02);

$\operatorname{subplot}(2,2,2)$

subimage $(\mathrm{J})$

title('Noisy Image')

$\mathrm{L}=$ medfilt2(J,[3 3$]$ );

subplot(2,2,3);

$\operatorname{imshow}(\mathrm{L})$

title('Noisy Image filtered by median filter')

c.function logarithm_Callback(hObject, eventdata, handles)

global im

$\mathrm{I} 2=\mathrm{im} 2$ double(im);

$\% \mathrm{~J}=1 * \log (1+\mathrm{I} 2)$

$\mathrm{J} 2=2 * \log (1+\mathrm{I} 2)$

$\% \mathrm{~J} 3=5 * \log (1+\mathrm{I} 2)$;

axes(handles.axes2);

imshow $(\mathrm{J} 2)$ 


\section{The questionnaire distributed}

Section 1: General information

1. Name (optional):

2. Sex: Male [ ]

Female [ ]

3. Age: 20- less than 30 [ ] 30 - less than 40 [ $]$ Medical image Technician [

4. Job: Medical Doctor [

5. Years of Experience: less than 5[ ] 5-less than10 [ ] 10-less than20 [ ]

6 . Further education in the area of medical image processing techniques is important:

Yes [ ] No [ ]

7. In case the medical image is up normal: The treatment will be as follows:

-Repeating the medical image [ ]

-Processing the medical image [ ]

Section 2: The effects of medical image processing techniques using MatLab package:

\section{Histogram equalization technique.}

Please put the sign correct $(\sqrt{ })$ in the suitable place on the table Below:

\begin{tabular}{|c|c|c|c|}
\hline & Yes & Neutral & No \\
\hline $\begin{array}{l}\text { 1. The resolution in processed medical image is better than the origin } \\
\text { medical image }\end{array}$ & & & \\
\hline $\begin{array}{l}\text { 2. The contrast Sensitivity in processed medical image is better than } \\
\text { origin medical image. }\end{array}$ & & & \\
\hline $\begin{array}{l}\text { 3. Noises in processed medical image are less than in the origin medical } \\
\text { image. }\end{array}$ & & & \\
\hline $\begin{array}{l}\text { 4. The blur in processed medical image is less than in the origin medical } \\
\text { image. }\end{array}$ & & & \\
\hline $\begin{array}{l}\text { 5. In general the processed medical image (new medical image) is better } \\
\text { than the origin medical image in order to diagnose }\end{array}$ & & & \\
\hline
\end{tabular}

2. Median filter technique.

Please put the sign correct $(\sqrt{ })$ in the suitable place on the table Below:

\begin{tabular}{|c|c|c|c|}
\hline & Yes & Neutral & $\mathrm{No}$ \\
\hline $\begin{array}{l}\text { 1. The resolution in processed medical image is better than the origin } \\
\text { medical image }\end{array}$ & & & \\
\hline $\begin{array}{l}\text { 2. The contrast Sensitivity in processed medical image is better than } \\
\text { origin medical image. }\end{array}$ & & & \\
\hline $\begin{array}{l}\text { 3. Noises in processed medical image are less than in the origin medical } \\
\text { image. }\end{array}$ & & & \\
\hline $\begin{array}{l}\text { 4. The blur in processed medical image is less than in the origin medical } \\
\text { image. }\end{array}$ & & & \\
\hline $\begin{array}{l}\text { 5. In general the processed medical image (new medical image) is better } \\
\text { than the origin medical image in order to diagnose }\end{array}$ & & & \\
\hline
\end{tabular}

\section{Logarithm transformation}

Please put the sign correct $(\sqrt{ })$ in the suitable place on the table Below:

\begin{tabular}{|c|c|c|c|}
\hline \multirow{2}{*}{$\begin{array}{l}\text { The resolution in processed medical image is better than the origin medical } \\
\text { image }\end{array}$} & Yes & Neutral & No \\
\hline & & & \\
\hline $\begin{array}{l}\text { The contrast sensitivity in processed medical image is better than origin medical } \\
\text { image. }\end{array}$ & & & \\
\hline Noises in processed medical image are less than in the origin medical image. & & & \\
\hline The blur in processed medical image is less than in the origin medical image. & & & \\
\hline $\begin{array}{l}\text { In general the processed medical image (new medical image) is better than the } \\
\text { origin medical image. }\end{array}$ & & & \\
\hline
\end{tabular}

